\section{THE ACIDITY OF NORMAL URINE.}

BX JAMES REOCH, M.A., M.B.,

DFMONSTRATOR OF PRACTICAL PHYSIOLOGX, COLIBGE OF MEDTOMNE, NEWCASTLE-ON-TXNE.

IN this paper I purpose giving an account of some experiments as a contribution towards the solution of several debated questions.

And first in regard to the acid urinary fermentation. The state of our knowledge on this subject might be summed up, as in Watts's Dictionary of Chemistry, by merely stating that it is affirmed by Scherer, but denied by Bence Jones. Now I examined many urines, and followed more than twenty day by day until alkalinity bad nearly set in, and in not more than three was there any increase of acidity, but generally there was a decrease each day; so that, while not denying that some urines may undergo acid fermentationfor we know that alcohol, when taken into the system, is largely excreted by the urine, and may there undergo the acetic-acid fermentation,-yet I entirely agree with Bence Jones, that urine does not normally undergo any increase of acidity after being voided. It appears to me, however, that the acid-fermentation theory has been supported principally by affording an easy explanation of some clinical facts regarding uric acid, and if these can be shown to be capable of a different interpretation, the theory will fall to the ground. These facts are, that uric acid never appears as a precipitate immediately after urine is voided, and that it is often not deposited until long after the urine has cooled down to the temperature of the air. Moreover, it is an acid which is very little soluble in water, either hot or cold; and it is therefore held as trebly proved that it is formed by acid fermentation.

In some experiments I made on the acidity of uric acid, I found that its acidity was the same whether dissolved in caustic soda or in solution of sodic phosphate, which latter salt is beliered by all supporters of acid fermentation to be the solvent of uric acid in the urine by forming urate of soda and acid phosphate. Evidently, therefore, sodic phosphate may be regarded as a mixture of acid phosphate and soda. I do not say that this is its molecular constitution, but it bebaves towards uric acid as if it were, and therefore, if we investigate the relations of uric acid to soda, we shall discover those it bears to sodic phosphate. I shall therefore describe fully the results of one or two experiments, merely remarking that $I$ have repeated them several times with the same results.

I took two standard solutions-one of $\mathrm{HCl}$ of strength 2 per cent., and one of caustic soda of which 4 cc. neutralised 2 ce. of the $\mathrm{HCl}$ solution. I dissolved $43 \mathrm{mgrms}$. of uric acid from urine (unpurified) in $4 \mathrm{cc}$. of soda solution by the aid of heat, and titrated with $\mathrm{HC}$. A precipitate formed at once, which dissolved on shaking. After $1 \frac{1}{2}$ ce. had been added the precipitate was permartent, and by the microscope was shown to be urate of soda. 'T'be fluid was now acid, and held simply $\mathrm{NaCl}$ and urate of soda in solution; but on adding HCl up to $2 \mathrm{cc}$. and stirring, the precipitate changed its character, and by the microscope was shown to be uric acid with scarcely a trace of urate. On boiling, the precipitate did not dissolve. I then added $4 \mathrm{cc}$. of soda solution and heated; the precipitate dissolved readily. But on boiling and then dropping in $2 \mathrm{cc}$. $\mathrm{HCl}$ quickly, no precipitate appeared for some time, and at $60^{\circ} \mathrm{C}$. was very incomplete; but on brisk stirring it was complete at $55^{\circ}$. Adding 4 cc. of soda and boiling again, and then $2 \mathrm{cc}$. $\mathrm{HCl}$, the precipitate did not appear till $60^{\circ}$, was incomplete at $29^{\circ}$, and on stirring quickly was complete at $26^{\circ}$. This process being repeated gave $45^{\circ}$ for first appearance and $25^{\circ}-$ $2 \theta^{\circ}$ for completeness; on repeating it again the precipitate did not appear complete for a very long time. In all these cases the precipitate was verified to be uric acid by the microscope, and did not dissolve on subsequent boiling.

I then made a solution of nearly the same strength as the urine by dissolving $10 \mathrm{mgrms}$. of impure uric acid in $3.2 \mathrm{ec}$. of soda, adding $20 \mathrm{ce}$. of water and heating to $40^{\circ} \mathrm{C}$. On then adding $1.6 \mathrm{cc}$. $\mathrm{HCl}$ the fluid should have contained only $\mathrm{NaCl}$ and uric acid; but no precipitate was observable, even though the fluid was agitated and allowed to stand for twenty-four hours.
It appears, therefore, that the fact that uric acid does not crystallise out for some time depends on its molecular constitution, and not on any increase of acidity, and that from solutions so dilute as urine it may not crystallise out at all except under favourable conditions. I noticed also that when the bulb of the thermometer was moved about, when the uric acid was near its crystallising point white clouds of uric acid were seen following it, showing that while temperature has the greatest influence in determining its crystallisation, agitation and the presence of a foreign body are also adjuncts. Much the same explanation will account for urates not always depositing themselves when the urine cools. If anything were wanting to support these views, it would be the well-known fact that you do not get uric acid for some time even when you add a strong mineral acid to urine. Even the strongest supporters of acid fermentation admit that you must wait twenty-four hours, and that fortyeight hours is not too short a time to allow all the uric acid to fall down. Why, then, should a deposit of uric acid after twenty-four hours demand any greater increase of acidity than what is obtained in the body itself?-for though I have described $\mathrm{HCl}$ in my experiments, oxalic or any acid stronger than uric would do equally well. I therefore think that, given the three factors, uric acid, soda, and acid, you may, by varying their mutual quantity and dilution, produce all the phenomena presented by uric acid and urates without having recourse to any imaginary increase of aciditiy.

Secondly, in regard to the alkaline fermentation. It is usually stated that urine remains acid for a few days at the same degree of acidity, and then suddenly begins to undergo the alkaline fermentation; and this statement is supported by the experiments of Bence Jones. From more than twenty urines which I followed daily towards alkalinity I take the first ten, and average their acidity :-

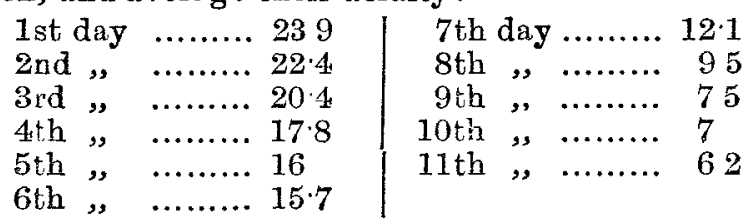

On the 11th day one or two became alkaline, but I give the average of the remainder. It will thus be seen that my experiments differ entirely from those of Bence Jones, and that I believe the urine begins to decompose from the moment of emission; nay, I shall show cause for believing that this process berins within the bladder itself, and that the point of neutralisation is reached, not by a sudden impulse, but as the result of a regularly progressive series of changes. Once, however, the point of alkalinity is reached, decomposition-sometimes, though by no means always or even generally-goes on with renewed vigour, as the following case will show:-

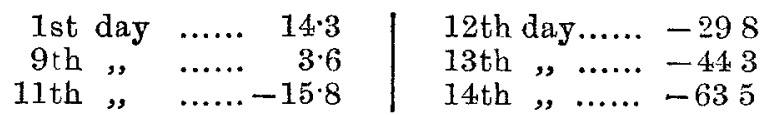

This urine, therefore, though it took ten days to lose its acidity, yet, after it had become neutral, it gained more alkali day by day than it had previously had of acid altogether.

Another common, indeed almost universal, opiuion is, that the cause of this fermentation lies in the muens of the urine. Now I shall attempt to show, hy many converging lines of proof, that progressive oxidatiun of the uric acid is the real agent in this change. I di not lay much stress on the observations of Neuhauer and Vugel on this subject, because in one part of their brok they say that the mucus canses the acid fermentation, and in another that it causes the alkaline. It appears to me improbable that it can do botb, and, according to my experiments on filtered and unfiltered urine, it does neither. I found, while examining the aeidity of urines, that the average of twenty specimens of urina sanguinis lost 36 per cent. acidity on boiling, and the same number of urina cibi 30 per cent. It cannot be that from 30 to 36 per cent. of the acidity of urine is due to a volatile acid such as $\mathrm{CO}_{2}$. So I filtered $40 \mathrm{cc}$. of urine and boiled $20 \mathrm{cc}$. for fifteen minutes, water being added up to $20 \mathrm{cc}$. The boiled and unboiled urines were put into separate test-tubes and 20 drops of $\mathrm{HCl}$ added to each. The next day the precipitated uric acid in each was weighed: from the bsiled urine $7 \mathrm{mgrms}$. were recovered, from the unboiled 11 ; in another experiment $18 \mathrm{mgrans}$. were got from the boiled 
urine, and 22 from the unboiled, besides a few milligrammes which adhered to the sides of the test-tube in the unboiled urines with too great tenacity to be got off by washing. Again, while examining the precipitate of uric acid in the first experiment I have mentioned in this paper, I noticed that while the crystals which precipitated naturally were clear and colourless, yet after the fluid was boiled, though they did not dissolve, they presented more or fewer granules on their surface, similar to the globules of gas developed in uric acid crystals precipitated by nitric acid; for on adding the latter acid to a series of test-tubes containing 2 cc. of urine each, it will be found that if from four to twelve drops or so are used the uric acid crystallises out in twentyfour hours, but the crystais are granular. If a larger quantity of $\mathrm{HNO}_{3}$ is used, they do not come out at all, because they are broken up and dissolved. The same thing was seen in hot weather on comparing two specimens of uric acid on a glass side, one of which had been protected by a covering glass, the other not, but simply protected from dust. When examined the next day, the crystals in the one were clear, but in the other granular; so also after warming a glass slide with a precipitate of uric acid on it, the crystals clear at first, appearing intensely granular. I have verified these results by repeated observation, so that I am thorougly convinced of their correctness, and $I$ would add that this oxidation seems to begin within the bladder itself, for $\mathrm{CO}_{2}$ and $\mathrm{N}$ are found free in urine, and yet comparatively no $\mathrm{O}$, which ought to be the case if these gases were derived from the blood; they are, however, well known to be the products of the oxidation of uric acid, and it therefore would appear that it is to uric acid and not to mucus we must look for an explanation of the subsequent changes in urine; indeed, I regard the function of mucus as protective, for by increased secretion it will prevent any evil result from the irritation of urine decomposing in a paralysed bladder. During the whole period of decreasing acidity the urea seems to remain unchanged; it then begins to decompose, but by what process is not yet clear. The ordinary theory that a peculiar ferment, probably an organic being, causes it to assume two molecules of water and become carbonate of ammonia is wholly unproved; but without doubt, whether it be thus or by a process analogous to the continuous etherification process that carbonate of ammonia is formed, its discovery must throw much light on one of the most obscure departments of physiology. The period at which the acidity of urine ceases varies very greatly, both with the temperature of the air and with the form of the vessel in which it is contained. Small quantities of urine in a test-tube become alkaline very readily, and the more so if not originally very acid; indeed, the addition of $\mathrm{HCl}$ or other strong acid will delay the alkaline fermentation of urine indefinitely. If the urine be put in a tall, narrow glass offering not more than a square inch of surface, it may remain acid for a fortnight even in warm weather; but the temperature of the air varies from hour to hour, rising towards midday and falling afterwards, and I have often noticed the temperature of the urine rising every hour in a corresponding manner, but always $1^{\circ}$ or $1.5^{\circ} \mathrm{C}$. lower in the forenoon than the air. While, therefore, the urine in a vessel follows the changes of the atmosphere, it is always an hour or two behind, probably from the greater specific heat of water. Even in these cases, therefore, the small surface exposes incessantly fresh particles of contained uric acid to oxidation, and thus hastens its ultimate decomposition.

Thirdly.-It has been much debated whether any increase of acidity takes place after meals, and Bence Jones and Roberts especially have strongly denied this. Now though my experiments entirely agree with theirs in that $I$ have invariably found $10 \mathrm{cc}$. of the morning urine contain more acid than $10 \mathrm{cc}$. at any time after breakfast, yet $I$ think the conclusion they draw is not valid. The proper stimulus of the bladder is distension, and it seems therefore that in determining the acidity of the morning urine, and comparing it with that after food, its quantity and the time of its secretion must be taken into account. When this is done I think that there can be no question that the acidity of the urine is largely increased by food. The mean of twenty experiments on urina sanguinis gave the acidity as 17 , as compared with 14 for the same number on urina cibi; but the specific gravity was also diminished in the latter case, and the phosphates were nearly halved in quantity; the time of secretion of equal quantities was not more than half. It appears to me, therefore, that while the acidity of urine is always bigher in the morning than at any other time for a given quantity of urine, yet this effect is entirely due to its greater concentration and longer period of secretion, and that the amount of acid, absolutely, though not relatively to the water, is largely increased by food.

\section{ON VENOUS ANEURISM AND ADAPTATION OF TISSUES.}

By A. VANS BEST, M.D., F.R.C.S.

IN the spring of this year I was asked to examine a swelling upon a girl's forearm. Her age was about fourteen; she was quite healthy; and the history of the swelling was obscure. I found a very peculiar tumour, larger than a walnut, just over the anterior superficial radial vein. It was emptied by pressure on the distal side. There was no pain, except a slight undulatory throbbing. I diagnosed it as a dilated sacculated valve of the vein, and removed it, tying the vein above and below.

The appearance of the sac after being cleaned out was exactly like the interior of an auricle; the capacity was larger than the point of a thumb; and the walls showed trabeculæ, and even muscular fibre, under the microscope. The wound healed well.

I could elicit no history of injury or puncture, and it is difficult to trace how such a tumour occurred. It was different from a varicose thrombus occurring in the lower extremity. It was a case of pure venous aneurism, with modified and organised walls; and, from its structure, might have had contractile power. There was no arterial communieation, and only one dilatation of the vein. The preparation well shows the interior of the tumour.

Adaptation of tissue, also, is seen wonderfully at the neck of the bladder and in the perineum. In the event of the bursting of the membranous portion of the urethra, occasioned by old stricture, we not unfrequently find, after all the immediate dangers have been combated, that a deputy bladder has formed, and the loose cellular tissue become so matted together and covered by a pseudo-mucous membrane as to form really a safe reservoir where the surplus water can be confined. This is emptied generally by an instrument or by manual pressure; but it also of ten bas contractile force, as the patient is aware of its emptying and filling. Great adaptation of tissue must have occurred in these cases. In one, after external section straight to the bladder, I cured the patient of his mass of cartilaginous strictures, but his deputy bladder continued to be evacuated by pressure inside the left tuberosity of the ischium, and when once it flowed he strained hard. In another case the whole calibre of the urethra (membranous) was fusiform, exactly like Aveling's transfusion bag. This anterior bladder was constantly emptied by the patient, who carried a flexible catheter, which relieved him for twenty minutes. With great difficulty I got an instrument into the true bladder, but without any benefit, and had to trust to suppositories to allay irritability.

Other examples of adaptation of mucous membrane and skin are to be seen in the cure of severe cases of ectropion and entropion; also during the cure of fistula lachrymalis, or after division of Steno's duct; in the lifting of the middle portion of the upper lip to form a columna, and in sepa rating the cheek from the jaw to obtain material for a fresh lip in epithelioma.

Aberdeen.

\section{IMPROVED DOUBLE STETHOSCOPE.}

\section{BY CARTWRIGHT REED, M.D.}

THE improvements claimed for this instrument over others of its class are as follows: -1 . The ends of the elastic tubing (A $A$ and $B$ B) are visible. At first impression this may not be considered an improvement; but I was in. formed by an eminent auscultator that on first using the 